\title{
Cognition and Comprehension in Students Learning Foreign Language
}

\author{
Cecil Allen ${ }^{1 *}$ and Susan Thomas ${ }^{2}$ \\ ${ }^{1}$ Independent Researcher and English Instructor, Vietnam \\ ${ }^{2}$ Adjunct Associate Professor, RMIT University Vietnam, Vietnam \& Professor Okanagan School of Business, Canada \\ *Corresponding author: Cecil Allen, Independent Researcher and English Instructor, Vietnam
}

\begin{abstract}
Learning is a mental feat that one must overcome especially with a subject that is difficult or if one dislikes. Learning a foreign language also presents its obstacles. Declarative memory and spatial recognition are the two types of memory recall within the hippocampus. Memory is a key aspect associated with language. As Instructors the delivery of materials and activities using short term memory stimulation is extremely important.
\end{abstract}

Keywords: Cognitive skills; Memory stimulation; Hippocampus; Foreign language; Activity-based learning

\section{Opinion}

It is human nature to have some level of apprehension or nervousness when taking on the journey of learning a new language. After all, learning anything, in itself, can be a challenge for many of us. Certainly, it takes effort and concentration. Learning is often seen as a definite mental feat that one must overcome, especially a subject or a concept that we may either dislike or fear. It has been seen that when it comes to Maths or Science, students may often become anxious or uncertain about learning and how he or she may fare in the end. This is a normal reaction to any challenging subject that requires serious study. But what about when it comes to taking on the task of learning a new language? A language that is nowhere close to one's native tongue. A language that presents itself as an obstacle course full of hurdles and mud pits, waiting to stop anyone in their tracks. Stop them way before they are able to get a good foothold and begin. But this is relative, often, to how a student may perceive learning something new. It could very well be the perception of growing up and already speaking their own native language and now facing the task of a new one.

Having said this, we know that the human brain is designed to function as a sponge when it comes to navigating anything new, especially languages. This is how our memory begins to become rooted and ready to recall any new experience. Our brain has an area within it called the hippocampus which is part of the Limbic system. When it comes to memory and recall, the hippocampus area of the human brain has a vast chore to accomplish. The recall of memory is so fast that we never, ever take consideration of how the brain even does it! Memory is the key to learning and interpreting any new experience especially those associated with language. In children and young teenagers, studies have shown that the brain reacts very markedly to the two types of memoryprocessing pathways that aid in learning. Declarative memory and spatial recognition are the two types of memory recall within the hippocampus that assist in memory processing [1]. Not only are these areas the key to learning in younger students, but research has shown that nerve cells in the brain continue to develop as we grow older [1].

The hippocampus happens to be one of the areas of the brain where nerve cells continue to proliferate and develop as we age, therefore, proving that an older adult student that is a non-native speaker is capable of recognizing and comprehending a new language. So, how does a student learn a new language? How is he or she able to recognize and then comprehend a new language? One part of the learning process is through the methodology of 
how they are taught. Delivery of materials and activities, such as writing, speaking, reading and grammar are extremely important for instilling the information so that the student is able to maintain what is presented. Another part of aiding the student in their cognition skills and comprehension is through short-term memory stimulation. It has been our experience that this process leads into and eventually becomes part of long-term memory. If either methodology or short-term stimulation are ill-presented, then there is probably not going to be a solidified foundation for that phase of learning.

To be certain of a good foundation, methodology and shortterm stimulation must be consistent. In our observation, we asked several students how they best remembered a new language which was being taught to them. Several responded that they were always able to remember any type of activity-based learning. It can be noted that activities stimulated the pathways of memory, within the hippocampus, that help to associate functional connectivity to what took place. Others said that it was a combination of activitybased and repetition-based learning. The repetition-based learning included the vocalization of words and phrases, as the words and phrases were often written or spelled out and connected to practical everyday situations. This type of stimulation for shortterm memory caused the students to hear and see what was taking place more vividly than if activity only. It has also been researched and proven that activity-based learning relates to physical exercise for the body [2,3], and this may be the cause for preservation and improvement of memory [2], and this may be one of the reasons that adult students may fare well in comprehending and maintaining a new language. The plasticity of the brain and memory

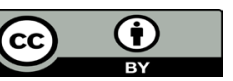

This work is licensed under Creative

Commons Attribution 4.0 License

To Submit Your Article Click Here: Submit Article have a directly proportional relationship to physical exercise [2]. Depending on whether the new language is phonetic or written, cognition and comprehension will vary from student to student. We all learn at different levels and paces. Since it is a foreign (new) language being taught to the student, there is the natural tendency to try to either associate the language with their native language, or empty their minds and allow their brains to accept and welcome whatever is being taught. Either way, the learning process will be experienced and handled the best way possible according to each individual student. This is something that a good instructor should be aware of periodically as they teach.

\section{Conclusion}

In conclusion, cognition and comprehension by the student is also a responsibility of the instructor. The instructor should conduct checks and balances to assure their daily goals of teaching go according to the lesson plan. In doing this, the learning experience is sure to be profitable and rewarding for the student. Otherwise, a student, young or old, does not have a way of measuring their accomplishments for any given day of instruction. Combination of the efforts of the student and guidance from the instructor are a formidable program for success.

\section{References}

1. Dresden D (2017) What is the hippocampus? Medical News Today.

2. Godman H (2014) Regular exercise changes the brain to improve memory, thinking skills. Harvard Health Publishing, Harvard Medical School.

3. Hayes SM, Alosco ML, Hayes JP, Cadden M, Peterson KM, Allsup K, Forman DE, Sperling RA and Verfaellie M (2015) Physical Activity Is Positively Associated with Episodic Memory in Aging. Journal of the International Neuropsychological Society 21(10): 780-790.

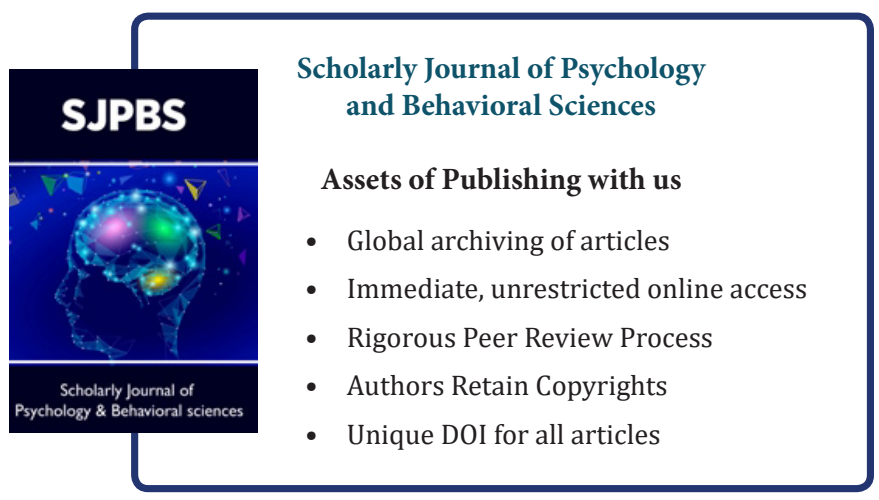

